\title{
Gene-Environment Interplay and Substance Use: A Review of Recent Findings
}

\author{
Izabela Milaniak $^{1} \cdot$ Bethany Watson $^{1} \cdot$ Sara R. Jaffee ${ }^{1}$
}

Published online: 28 September 2015

(C) Springer International Publishing AG 2015

\begin{abstract}
Substance use problems are chronic and common public health problems. We review recent studies that implicate genetic and environmental factors in their etiology. Although findings are mixed with respect to specific genotypes, some patterns are evident. For example, exposure to peers or parents who engage in high rates of substance use tends to exacerbate genetic diatheses or eliminate the protective effects of certain genotypes. We discuss reasons for mixed findings and highlight the need for translational research to advance understanding of gene function as well as new methods for using genomewide data in biologically relevant pathways.
\end{abstract}

Keywords Substance use · Genes · Gene x environment interaction

\section{Introduction}

Substance use problems, including cigarette smoking, alcohol abuse and dependence, and drug abuse and dependence, are chronic and common public health problems. According to 2012-13 data, $29 \%$ of adults in the USA met criteria for an alcohol use disorder (AUD) at some point in their lives and $14 \%$ met criteria in the past year [1]. In 2013, $18 \%$ of adults in the USA smoked cigarettes [2] and $13 \%$ used marijuana

Izabela Milaniak and Bethany Watson Joint first authors

This article is part of the Topical Collection on Transgenerational Considerations in Addictions

Sara R. Jaffee

srjaffee@psych.upenn.edu

1 Department of Psychology, University of Pennsylvania, 3720 Walnut Street, Philadelphia, PA 19104, USA
[3]. Tobacco and alcohol use rank among the top 10 preventable causes of deaths in the world [4].

Genetic factors play a role in the etiology and maintenance of substance use problems, with heritability estimates for persistent smoking, alcohol use disorders, and cannabis dependence falling between 50 and $70 \%[5,6]$. Genome-wide association studies (GWAS) and meta-analyses of GWAS have identified single nucleotide polymorphisms (SNPs) that are associated with alcohol dependence and smoking phenotypes [7-9]. In a review of these and candidate gene studies, Bühler et al. [10•] reported that the most robust associations involve SNPs in the alcohol metabolizing genes, the cholinergic gene cluster, and in the dopamine D2 receptor (DRD2) and Ankyrin repeat and kinase domain containing 1 (ANNK1) genes.

The effects of identified gene variants are small, with each SNP typically accounting for less than $2 \%$ of the variance in the phenotype - far less than that implied by heritability estimates $[11,12]$. One possibility is that substance use and dependence phenotypes are influenced by multiple genes of small effect. Although likely to be true, linear combinations of gene variants (i.e., polygenic risk scores) still have relatively small effects. Another possibility is that gene $\times$ gene and gene $\times$ environment interactions capture additional variation in substance use and dependence phenotypes. In support of this possibility, there is ample evidence from quantitative behavioral genetic studies that the heritability of substance use phenotypes varies as a function of the environment [13•]. In this review, we summarize findings from recent candidate gene studies that test gene $\times$ environment interactions $(\mathrm{G} \times \mathrm{E})$, focusing largely on variants that have been consistently associated with substance use phenotypes in gene association studies. We conclude with a critique of this literature and recommendations for future research.

Although this review covers gene $\times$ environment interactions, we note that gene-environment correlations are another 
mechanism by which gene-environment interplay influences risk and resilience for substance use phenotypes. Geneenvironment correlations describe genetically based individual differences in exposure to risk factors for substance use and we direct interested readers to recent papers on this topic by Hicks et al. [14] and Wills and Carey [15].

\section{Gene $\times$ Environment Interactions: Nicotine}

Quantitative behavioral genetic studies have shown that genetic influences on smoking are stronger in more permissive versus more restrictive environments. For example, genetic influences on adolescents' daily smoking are lower in states that impose higher taxes on cigarette sales and exercise greater control over cigarette vending machines and advertising than in states with less restrictive controls [16]. Similarly, the heritability of adolescents' daily smoking is highest in schools where the most popular students are smokers and the lowest in schools wherein the majority of students are non-Hispanic and White [17].

In addition to testing whether genetic influences on smoking are more pronounced in permissive versus restrictive environments, recent candidate gene studies have focused on the extent to which stressful life events moderate genetic influences on smoking behavior. Below, we review recent studies that test whether gene variants that have been consistently implicated in smoking phenotypes are moderated by adversity or by environments that facilitate smoking.

\section{Moderators of Serotonin Transporter Gene Effects} Variation in the serotonin transporter-linked polymorphic region $(5 H T T L P R)$ has been associated with an increased risk for nicotine dependence in both European American and African American smokers [18] and is hypothesized to be a marker for sensitivity to the environment [19]. As such, a number of studies have tested the hypothesis that effects of stressful life events and effects of more smokingpermissive environments on risk for smoking should be more pronounced among individuals who carry the short form (s allele) of the serotonin transporter polymorphism than among individuals who are homozygous for the long form (1 allele) of the gene.

Evidence in support of this hypothesis has been mixed. In one study of nicotine dependence in a sample of 256 alcohol-dependent adults, a history of childhood adversity was unrelated to nicotine dependence and the strength of the association did not vary as a function of 5HTTLPR genotype [20]. However, in another study of roughly 15 , 000 adolescents (age 11-22, $M=16.4$ ) from the National Longitudinal Study of Adolescent Health, adolescents drank more alcohol and smoked more cigarettes when attending schools in which peers engaged in higher rates of smoking and drinking, and this effect was more pronounced the more 5HTTLPR s alleles the adolescent carried [21]. A similar pattern of findings was detected in a different sample of 1519 adolescents; those who lived in neighborhoods in which a high proportion of their peers were smokers were at elevated risk for initiating smoking themselves [22].

Moderators of Dopaminergic Gene Effects Dopaminergic genes have been implicated in novelty-seeking hypotheses of smoking [23] and dopamine is involved in the reinforcing effects of nicotine in animal models [24]. In a study of 365 13- to 16-year-olds, however, $D R D 2$, dopamine receptor D4 (DRD4), and dopamine transporter (DATl) genotype were unrelated to smoking initiation and the strength of these associations did not vary as a function of the frequency or quality of parent-child communication, smoking-specific house rules [25], or parental, sibling, or peer smoking [26].

Moderators of Cholinergic Gene Effects A number of cholinergic receptor genes are involved in producing subunits of the neuronal nicotinic acetylcholine receptor, which plays an important role in chemical signaling in the brain [27]. Sequence variants in the cholinergic gene cluster genomic regions $15 \mathrm{q} 25,7 \mathrm{p} 14,8 \mathrm{p} 11$, and $19 \mathrm{q} 13$ predict number of cigarettes smoked per day at genome-wide levels of significance [28]. In a study of 2206 European American adults, Xie et al. [29] reported that childhood adversity increased the risk for nicotine dependence in men and women and this effect was exacerbated in men who were homozygous for the A allele in rs16969968 of the CHRNA5 gene.

Moderators of Polygenic Risk Effects Because genetic influences on smoking are likely to comprise hundreds of genes of small effect, some researchers have created polygenic risk scores based on GWAS meta-analyses. For example, Meyers et al. [12] constructed a polygenic risk score comprising 6 variants that were significantly associated (at $p<5 \times 10^{-7}$ ) with cigarettes smoked per day in a meta-analysis of GWAS of smoking in African American samples [7]. In a majority African American sample from Detroit $(n=399)$, the association between the genetic risk score and smoking was greater for those who had experienced a higher number of lifetime traumatic events and was diminished among individuals living in neighborhoods characterized by higher levels of social cohesion [12].

\section{Gene $\times$ Environment Interactions: Cannabis}

Moderators of Dopaminergic Genes Several recent studies support the hypothesis that DRD4 7-repeat carriers are more 
sensitive than non-7-repeat carriers to environmental influences on cannabis use. For example, in a study of 311 adolescents ( $M$ age 15.2, $S D=0.56$ ) followed for 4 years, those with the DRD4 7-repeat polymorphism engaged in higher rates of cannabis use when parental monitoring was low and lower rates of cannabis use when parental monitoring was high compared with adolescents who lacked the 7-repeat polymorphism [30]. Similarly, insecure attachment style (avoidant or anxious) is more strongly associated with cannabis use and smoking (but not alcohol binging) among young adults (24 years, $n=839$ ) who carry the DRD4 7-repeat than among non-carriers [31]. Finally, in a study of 399 rural African-American adolescents (Wave $1 M$ age $=17$ years), those who had experienced high rates of stressful life events showed the steepest escalations in drug use from adolescence to young adulthood, particularly if they carried the DRD4 7-repeat variant (Brody et al., 2012). Carriers also showed the largest increases in two proximal risk factors for drug use: affiliation with drug-using companions and drug vulnerability cognitions. When these proximal risk factors were entered into the model, the interaction between DRD4 genotype and stressful life events became non-significant, suggesting that for a genetically vulnerable group, stressful life events may increase exposure to more proximal risk factors for drug use (Brody et al., 2012).

Finally, in a study of a DRD2 variant (TaqIA), Vaske [32] reported that although A1 and A2 homozygotes showed steeper increases in marijuana use over a 1-year period when their parents did (versus did not) allow them to set their own curfews, the pattern of results was the opposite for heterozygotes who showed steeper increases in marijuana use when parents did not allow them to set their own curfew (Vaske, [32]).

Moderators of 5HTTLPR Effects The effect of childhood neglect on marijuana use has been shown to be stronger in females (but not males) who are homozygous for the short form of 5HTTLPR [33]. Another study tested whether $5 H T T L P R$ genotype moderated the effect of neighborhood factors (i.e., residential stability and neighborhood disadvantage) on past-year alcohol use, binge drinking, and marijuana use via a harmonized data set comprising 5 longitudinal studies of African American children and adolescents with data points spanning ages 10-24 $(n=2689)$. Residential instability was associated with higher levels of substance use as well as a steeper gradient in the increase of substance use from age 10 to 24 , particularly for carriers of the 5HTTLPR s allele [34•].

Moderators of Inferred Genetic Risk In a large-scale Swedish population study of drug abuse, Kendler and colleagues [35] found that peer deviance, measured at the population level as the proportion of similar-age individuals living in the same community who went on to develop drug abuse, strongly predicted individual drug abuse; the pathogenic effect of peer deviance was stronger when individuals were at heightened genetic risk, as determined by family history of drug abuse, weighted for biological relatedness to the proband.

\section{Gene $\times$ Environment Interactions in Alcohol Use Disorder}

In a review of the evidence from quantitative behavioral genetic studies, Dick and Kendler [13•] concluded that genetic influences on alcohol use are stronger in environments that make alcohol more readily accessible or that promote pro-drinking norms than in less permissive environments. Consistent with these findings, a study of adolescents from the National Longitudinal Survey of Adolescent Health showed that a genetic propensity to use alcohol was suppressed among adolescents who attended high achieving schools (where, presumably, there was strict social control of drinking) but was manifest among adolescents who attended lower achieving schools [36].

Moderators of Alcohol-Metabolizing Genotypes The most consistent and well-replicated genetic variants linked to alcohol use disorders specifically are functional polymorphisms in the alcohol dehydrogenase $(A D H 1 B)$ and aldehyde dehydrogenase $(A L D H 2)$ genes that code for alcohol metabolizing liver enzymes (e.g., $[37,38])$. The high activity $A D H 1 B^{* 2}$ (the minor A) allele and the inactive $A L D H 2 * 2$ have been shown to have protective effects on the development of alcohol use disorders.

In general, the protective effects of these two alcoholmetabolizing variants seem to be more robust in low-risk environments and attenuated in high-risk environments marked by high stress and low social control. For example, in a racially diverse sample $(n=4053)$, the protective effect of the A allele (AA/AG genotype) was reduced in European American men exposed to childhood adversity, but no such interaction effect was observed for European American women or for African Americans [39]. Similarly, in a sample of adolescents (12-22 years) from the Collaborative Study of the Genetics of Alcoholism $(n=1550)$, the protective effect of the $A D H 1 B$ A allele on early drinking milestones was also negated when adolescents reported that most of their best friends drank alcohol [40]. In another adolescent sample that included East Asian adoptees $(n=365)$, researchers found that the protective effects of the $A L D H 2 * 2$ allele on alcohol dependence increased over the course of adolescence and young adulthood, but this effect was reduced in families where parents' use and misuse of alcohol was high, though not when siblings or peers were heavy drinkers [41•]. In contrast to 
these findings, a study of Jewish Israeli, mostly male adults $(n=1,143)$ found that the protective effect of the $A D H 1 B$ A allele was stable regardless of an individual's exposure to childhood adversity, but the risk-promoting effects of the GG genotype were more pronounced among individuals who experienced relatively high versus low levels of childhood adversity [42].

Moderators of Dopamine and Opioid Genes The catecholO-methyltransferase (COMT) gene encodes an enzyme that metabolizes dopamine and is implicated in dopamine functioning in the prefrontal cortex [43]. The COMT gene includes a common functional polymorphism Val158Met that is associated with lower COMT enzyme activity and, therefore, reduced dopamine functioning in the prefrontal cortex [44]. In a case control design with male abstinent alcohol-dependent patients and their matched controls $(n=$ 110), researchers found that carriers of the low-activity Met allele (Met/Met or Val/Met) who were exposed to childhood adversity had a higher risk of developing severe alcohol dependence than individuals homozygous for the Val allele [45]. In contrast, the DRD2/ANKK1 Taq1A A1 genotype did not interact with childhood adversity in predicting alcohol dependence [45].

The COMT Met allele has also been shown to increase risk for alcohol use in more versus less permissive environments. In an ongoing cohort study $(n=285)$, 19-yearolds who carried the Met/Met genotype were differentially susceptible to effects of parental involvement and supervision: under conditions of low parental involvement or supervision, youth who were homozygous for the Met allele drank more alcohol than Val allele carriers, but under conditions of high parental involvement or supervision, Met homozygotes drank less alcohol than Val allele carriers [46]. In contrast, Val allele carriers were moderate drinkers whose alcohol use was unrelated to parental involvement or supervision [46].

The opioid receptor mu 1 (OPRM1) gene has also become a focus of study in research on alcohol use because of the involvement of the endogenous opioid system in the reinforcing and addictive effects of alcohol through the dopaminergic pathway. The presence of the $G$ allele genotype $(\mathrm{GG} / \mathrm{AG})$ in the A118G SNP of OPRM1 has been associated with increased hedonic reactions, craving, and excess mesocorticolimbic activation to alcohol use [47]. In a case-control design of adolescents with alcohol use disorder $(n=104)$, Miranda and colleagues [48] found that a higher proportion of the high-risk $G$ allele carriers (AG/GG genotype) met criteria for alcohol use disorder compared to the low risk AA homozygotes and this effect was amplified when parental monitoring was low and deviant peer affiliation was high. Using a larger sample $(n=$ 529), Chassin and colleagues [49] found that exposure to deviant peers was associated with higher levels of alcohol use disorder symptoms for women (but not men) who were $\mathrm{G}$ allele carriers, but women with the AA genotype were not as susceptible to deviant peer influences.

Genetically based individual differences in response to parental rule setting have also been observed. In a study of 596 adolescents, those whose parents set alcohol-specific rules were less likely to be on a heavy drinking trajectory from 12 to 16 years than on a light drinking trajectory and this effect was most pronounced among OPRM1 G allele carriers [50]. In a different sample of 241 12- to 16-year-olds, Pieters and colleagues [51] also found that when parents set strict, alcohol-specific rules, weekly alcohol consumption was low regardless of OPRM1 genotype, but when parents did not set strict alcohol-specific rules, OPRM1 G allele carriers engaged in higher rates of alcohol consumption than AA homozygotes. Furthermore, the same pattern was evident in the DRD2 genotype; adolescents who carried the high-risk $\mathrm{T}$ allele were more susceptible to parental rule setting than adolescents who were homozygous for the low-risk $\mathrm{C}$ allele.

Moderators of Clock Genes Clock genes that regulate the molecular components of the circadian rhythm have been implicated as major components of the development of alcohol disorders [52]. Using mouse models, researchers have found that circadian rhythmicity, which governs how an individual adapts to their internal and external environment, shapes the rewarding effects of alcohol use [53]. Several studies have found links between clock genes and alcohol dependence in humans $[54,55]$ and in a sample of 268 young adults, the association between stressful life events and alcohol use was shown to be stronger among individuals who carried the AA genotype of the period circadian clock (PER) gene than among $\mathrm{G}$ allele carriers [56].

Moderators of Impulsivity-Related Genes Candidate gene studies have consistently identified associations between alcohol dependence and AA genotype for rs 279871 of the gammaaminobutyric acid A receptor alpha 2 (GABRA2), which influences the effectiveness of inhibitory processes in the brain that modulate impulsivity and emotional reactivity [57]. Using data from the Collaborative Study on the Genetics of Alcoholism $(n=2281)$, Perry and colleagues [58] found that experiencing higher levels of positive daily life events was associated with reduced risk for alcohol dependence for men with the high-risk AA genotype but not for men with the lowrisk genotype $(\mathrm{AG} / \mathrm{GG})$ or for women, regardless of genotype.

In the central nervous system, activation of the neuropeptide $\mathrm{S}$ receptor (NPSRl) promotes arousal and anxiety [59]. Based on studies with rodents, researchers have hypothesized that the low-activity AA allele is more frequently associated with anxiety and fear while the high-activity TT allele is linked to impulsivity [60]. Using data from the longitudinal 
Estonian Children Personality Behavior and Health Study ( $n=593$, age range 15-25 years), Laas and colleagues [61] reported gender differences in the effects of NPSR1 genotype on risk for AUD; for women, A allele carriers (AA/ AT) were more likely to have been diagnosed with alcohol use disorder by age 25 than individuals who were homozygous for the $\mathrm{T}$ allele. In contrast, for men, $\mathrm{T}$ allele carriers were at elevated risk for an alcohol use disorder diagnosis and engaged in more harmful alcohol use than AA carriers. Furthermore, the association between NPSR1 genotype and alcohol use disorder was stronger for men (but not women) who were exposed to higher versus lower levels of stressful life events in the past year.

Moderators of Polygenic Risk Salvatore et al. [62•] used GWAS data from the Avon Longitudinal Study of Parents and Children to create a polygenic risk score for alcohol problems which was then applied to a sample of Finnish twins ( $n=$ 1162). The polygenic risk score predicted alcohol problems in the Finnish sample and the effect was more pronounced under conditions of low parental knowledge or high peer deviance than under conditions of high parental knowledge or low peer deviance.

\section{Conclusions}

Although there is substantial evidence from quantitative behavioral genetic studies that genetic influences on substance use phenotypes vary across environments, evidence of gene $\times$ environment interaction is mixed in candidate gene studies. There are at least three explanations for such mixed results. First is the well-known problem that most candidate gene studies are statistically under-powered to detect gene $\times$ environment effects (e.g., [63]). Larger, better-powered samples will not guarantee replicable results, however. Statistical tests of interaction remain highly sensitive to scale in large and small samples (e.g., [64]). Moreover, as sample sizes increase, it becomes logistically and financially challenging to collect fine-grained measures of the environment. Although pooling studies has aided efforts to identify genetic main effects, there is likely to be substantial between-study variability in measurement of the environment and such measures will not be easily aggregated for the purposes of testing $\mathrm{G} \times \mathrm{E}$.

On a more optimistic note, many of the environments that have been shown to moderate genetic effects in twin studies are readily available from administrative data that are standardized across samples and easy to append to large-scale survey studies (e.g., socioregional variables). Other moderators can be cheaply and reliably ascertained through written or online surveys administered to large numbers of people (e.g., religious observance, substance-use-specific rule-setting). Moreover, methods are being developed to harmonize datasets that include distinct but related constructs [65]. Another potential solution is to derive polygenic risk scores from meta-analyses of GWAS and to apply these scores in samples with rich measures of the environment (e.g., [12, 62•]).

A second explanation for mixed findings is that our hypotheses are insufficiently biologically and environmentally informed. It is notable, for example, that some of the most replicable $\mathrm{G} \times \mathrm{E}$ findings involve alcoholmetabolizing genotypes where the function of the gene, the exposure, and their joint effect on behavior is wellcharacterized. Cross-disciplinary and translational research with humans and animals is needed to (a) ascertain whether observed statistical interactions reflect actual biological processes and (b) use knowledge of gene function and environmental mechanisms to inform hypotheses about which gene variants should be expected to interact statistically with which environments.

The studies reviewed here point to genes and environments that confer risk and protection, but findings are inconsistent across studies. On the environmental side, parental substance-specific rule setting appears to constrain a genetic diathesis for alcohol use $[50,51]$ but not smoking [25]. More consistently, exposure to peers or parents who use substances appears to exacerbate a genetic diathesis for substance use $[21,22,35,48,49,62 \cdot]$ or eliminate the protective effects of a genotype that makes drinking alcohol aversive [40, 41•].

On the genetic side, 5HTTLPR 1 allele carriers engage in relatively low rates of substance use regardless of their exposure to adversity and instability, consistent with a diathesis-stress model (Vaske et al. [33]; Windle [34•]). In other cases, genotypes appear to be differentially susceptible to environments rather than reflecting purely risk or protection. Complicating this picture, some gene variants show patterns of differential susceptibility in response to certain environments but confer risk or protection in response to other environments [45, 46]. Such mixed findings point to the importance of using formal methods for testing competitive hypotheses about diathesis-stress versus differential susceptibility [66] and careful model specification [67].

In summary, substance use researchers have a theoretically informed and empirically supported approach to the selection of environments that constrain or facilitate substance use. The challenge for biosocial models of substance use risk is to fill in the gaps in our knowledge of addiction biology so as to inform the selection of gene variants and - in collaboration with bioinformaticiansto use GWAS data to develop a better understanding of how sets of genes in biologically relevant pathways interact with environments to increase risk for substance use and abuse. 


\section{Compliance with Ethics Guidelines}

Conflict of Interest Izabela Milaniak, Bethany Watson, and Sara R. Jaffee declare that they have no conflict of interest.

Human and Animal Rights and Informed Consent This article does not contain any studies with human or animal subjects performed by any of the authors.

\section{References}

Papers of particular interest, published recently, have been highlighted as:

- Of importance

1. Grant B, Goldstein R, Saha T, et al. Epidemiology of DSM-5 alcohol use disorder: results from the national epidemiologic survey on alcohol and related conditions III. JAMA Psychiatry. 2015;72(8): 757-66.

2. Jamal A, Agaku IT, O’Connor E, King BA, Kenemer JB, Neff L. Current cigarette smoking among adults in the United States, 20052013. Morb Mortal Wkly. 2014;63(47):1108-12.

3. National Institute on Drug Abuse. Marijuana [Internet]. 2015 [cited 2015 Jul 30]. Available from: http://www.drugabuse.gov/drugsabuse/marijuana.

4. World Health Organization. Global health risks: mortality and burden of disease attributable to selected major risks. Geneva, Switzerland: WHO Press; 2009.

5. Agrawal A, Lynskey MT. The genetic epidemiology of cannabis use, abuse and dependence. Addiction. 2006;101(6):801-12.

6. Verhulst B, Neale MC, Kendler KS. The heritability of alcohol use disorders: a meta-analysis of twin and adoption studies. Psychol Med. 2015;45(05):1061-72.

7. David SP, Hamidovic A, Chen GK, Bergen AW, Wessel J, Kasberger JL, et al. Genome-wide meta-analyses of smoking behaviors in African Americans. Transl Psychiatry. 2012;2(5), e119.

8. Furberg H, Kim Y, Dackor J, Boerwinkle E, Franceschini N, Ardissino D, et al. Genome-wide meta-analyses identify multiple loci associated with smoking behavior. Nat Genet. 2010;42(5):441-7.

9. Zuo L, Lu L, Tan Y, Pan X, Cai Y, Wang X, et al. Genome-wide association discoveries of alcohol dependence: GWAS of Alcohol Dependence. Am J Addict. 2014;23(6):526-39.

10. Bühler K-M, Giné E, Echeverry-Alzate V, Calleja-Conde J, de Fonseca FR, López-Moreno JA. Common single nucleotide variants underlying drug addiction: more than a decade of research. Addict Biol. 2015. Comprehensive overview of candidate gene, genome-wide, and family-based association studies of alcohol-, nicotine-, marijuana-, and cocaine-related phenotypes.

11. Hart AB, Kranzler HR. Alcohol dependence genetics: lessons learned from genome-wide association studies (GWAS) and postGWAS analyses. Alcohol Clin Exp Res. 2015;39(8):1312-27.

12. Meyers JL, Cerdá M, Galea S, Keyes KM, Aiello AE, Uddin M, et al. Interaction between polygenic risk for cigarette use and environmental exposures in the Detroit neighborhood health study. Transl Psychiatry. 2013;3(8), e290.

13. Dick DM, Kendler KS. The impact of gene-environment interaction on alcohol use disorders. Alcohol Res Curr Rev. 2012;34(3):31824. Critical review of quantitative and molecular behavioral genetic studies of alcohol use phenotypes and methodological critique of candidate gene $x$ environment interaction studies.
14. Hicks BM, Johnson W, Durbin CE, Blonigen DM, Iacono WG, McGue M. Gene-environment correlation in the development of adolescent substance abuse: selection effects of child personality and mediation via contextual risk factors. Dev Psychopathol. 2013;25:119-32.

15. Wills AG, Carey G. Adolescent peer choice and cigarette smoking: evidence of active gene-environment correlation? Twin Res Hum Genet. 2013;16(05):970-6.

16. Boardman JD. State-level moderation of genetic tendencies to smoke. Am J Public Health. 2009;99(3):480-6.

17. Boardman JD, Saint Onge JM, Haberstick BC, Timberlake DS, Hewitt JK. Do schools moderate the genetic determinants of smoking? Behav Genet. 2008;38:234-46.

18. Yang Z, Seneviratne C, Wang S, Ma JZ, Payne TJ, Wang J, et al. Serotonin transporter and receptor genes significantly impact nicotine dependence through genetic interactions in both european american and African american smokers. Drug Alcohol Depend. 2013;129(3):217-25.

19. Van IJzendoorn MH, Belsky J, Bakermans-Kranenburg MJ. Serotonin transporter genotype 5HTTLPR as a marker of differential susceptibility? A meta-analysis of child and adolescent geneby-environment studies. Transl Psychiatry. 2012;2(8), e147.

20. Mingione CJ, Heffner JL, Blom TJ, Anthenelli RM. Childhood adversity, serotonin transporter (5-HTTLPR) genotype, and risk for cigarette smoking and nicotine dependence in alcohol dependent adults. Drug Alcohol Depend. 2012;123(1-3):201-6.

21. Daw J, Shanahan M, Harris KM, Smolen A, Haberstick B, Boardman JD. Genetic sensitivity to peer behaviors: 5HTTLPR, smoking, and alcohol consumption. J Health Soc Behav [Internet]. 2013 Mar [cited 2015 Aug 7];54(1). Available from: http://www.ncbi.nlm.nih.gov/pmc/articles/PMC3659161/.

22. Daw J, Boardman JD, Peterson R, Smolen A, Haberstick BC, Ehringer MA, et al. The interactive effect of neighborhood peer cigarette use and 5HTTLPR genotype on individual cigarette use. Addict Behav. 2014;39(12):1804-10.

23. Laucht M, Becker K, El-Faddagh M, Hohm E, Schmidt MH. Association of the DRD4 exon III polymorphism with smoking in fifteen-year-olds: a mediating role for novelty seeking? J Am Acad Child Adolesc Psychiatry. 2005;44(5):477-84.

24. Corrigall WA, Franklin KBJ, Coen KM, Clarke PBS. The mesolimbic dopaminergic system is implicated in the reinforcing effects of nicotine. Psychopharmacol (Berl). 1992;107(2-3):285-9.

25. Hiemstra M, Engels RCME, Barker ED, van Schayck OCP, Otten $\mathrm{R}$. Smoking-specific parenting and smoking onset in adolescence: the role of genes from the dopaminergic system (DRD2, DRD4, DAT1 genotypes). PLoS ONE. 2013;8(4):1-10.

26. Hiemstra M, Kleinjan M, van Schayck OCP, Engels RCME, Otten R. Environmental smoking and smoking onset in adolescence: the role of dopamine-related genes. Findings from two longitudinal studies. PLoS ONE. 2014;9(1), e86497.

27. Schaaf CP. Nicotinic acetylcholine receptors in human genetic disease. Genet Med. 2014;16(9):649-56.

28. Thorgeirsson TE. Lung cancer susceptibility genes. J Thorac Oncol. 2011;6(6):S41-4.

29. Xie P, Kranzler HR, Zhang H, Oslin D, Anton RF, Farrer LA, et al. Childhood adversity increases risk for nicotine dependence and interacts with $\alpha 5$ nicotinic acetylcholine receptor genotype specifically in males. Neuropsychopharmacology. 2012;37(3):669-76.

30. Otten R, Barker ED, Huizink AC, Engels RCME. The interplay between parental monitoring and the dopamine D4 receptor gene in adolescent cannabis use. Yaragudri VK, editor. PLoS ONE. 2012;7(11), e49432.

31. Olsson CA, Moyzis RK, Williamson E, Ellis JA, Parkinson-Bates $\mathrm{M}$, Patton GC, et al. Gene-environment interaction in problematic substance use: interaction between DRD4 and insecure attachments. Addict Biol. 2013;18(4):717-26. 
32. Vaske J. Interaction of the TaqIA polymorphism and poor parental socialization on changes in adolescent marijuana use. Subst Use Misuse. 2013;48(3):258-64.

33. Vaske J, Newsome J, Wright JP. Interaction of serotonin transporter linked polymorphic region and childhood neglect on criminal behavior and substance use for males and females. Dev Psychopathol. 2012;24(01):181-93.

34. Windle M, Kogan SM, Lee S, Chen Y-F, Lei KM, Brody GH, et al. Neighborhood $\times$ Serotonin Transporter Linked Polymorphic Region (5-HTTLPR) interactions for substance use from ages 10 to 24 years using a harmonized data set of African American children. Dev Psychopathol. 2015; 1-17. Methodologically innovative approach that combines data from 5 longitudinal studies to increase power to detect whether effects of neighborhood factors on alcohol and marijuana use vary as a function of 5HTTLPR genotype.

35. Kendler K, Ohlsson H, Sundquist K, Sundquist J. Peer deviance, parental divorce, and genetic risk in the prediction of drug abuse in a nationwide swedish sample: evidence of environmentenvironment and gene-environment interaction. JAMA Psychiatry. 2014;71(4):439-45.

36. Benner AD, Kretsch N, Harden KP, Crosnoe R. Academic achievement as a moderator of genetic influences on alcohol use in adolescence. Dev Psychol. 2014;50(4):1170-8.

37. Gelernter J, Kranzler HR, Sherva R, Almasy L, Koesterer R, Smith $\mathrm{AH}$, et al. Genome-wide association study of alcohol dependence: significant findings in African- and European-Americans including novel risk loci. Mol Psychiatry. 2014;19(1):41-9.

38. Luczak SE, Glatt SJ, Wall TJ. Meta-analyses of ALDH2 and ADH1B with alcohol dependence in Asians. Psychol Bull. 2006;132(4):607-21.

39. Sartor CE, Wang Z, Xu K, Kranzler HR, Gelernter J. The joint effects of ADH1B variants and childhood adversity on alcohol related phenotypes in African-American and European-American women and men. Alcohol Clin Exp Res. 2014;38(12):2907-14.

40. Olfson E, Edenberg HJ, Nurnberger J, Agrawal A, Bucholz KK, Almasy LA, et al. An ADH1B variant and peer drinking in progression to adolescent drinking milestones: evidence of a gene-byenvironment interaction. Alcohol Clin Exp Res. 2014;38(10): 2541-9.

41. Irons DE, Iacono WG, Oetting WS, McGue M. Developmental trajectory and environmental moderation of the effect of ALDH2 polymorphism on alcohol use. Alcohol Clin Exp Res. 2012;36(11): 1882-91. This is one of few studies to test hypotheses about how genetic effects might vary across development during a period when alcohol use is, on average, on the increase.

42. Meyers JL, Shmulewitz D, Wall MM, Keyes KM, Aharonovich E, Spivak B, et al. Childhood adversity moderates the effect of ADH1B on risk for alcohol-related phenotypes in Jewish Israeli drinkers. Addict Biol. 2015;20(1):205-14.

43. Malhotra AK, Kestler LJ, Mazzanti C, Bates JA, Goldberg T, Goldman D. A functional polymorphism in the COMT gene and performance on a test of prefrontal cognition. Am J Psychiatry. 2002;159(4):652-4.

44. Tunbridge EM, Harrison PJ, Weinberger DR. Catechol-o-methyltransferase, cognition, and psychosis: Val158Met and beyond. Biol Psychiatry. 2006;60(2):141-51.

45. Schellekens AFA, Franke B, Ellenbroek B, Cools A, de Jong CAJ, Buitelaar JK, et al. COMT Val158Met modulates the effect of childhood adverse experiences on the risk of alcohol dependence. Addict Biol. 2013;18(2):344-56.

46. Laucht M, Blomeyer D, Buchmann AF, Treutlein J, Schmidt MH, Esser G, et al. Catechol-O-methyltransferase Val158Met genotype, parenting practices and adolescent alcohol use: testing the differential susceptibility hypothesis. J Child Psychol Psychiatry. 2012;53(4):351-9.
47. Ray LA, Barr CS, Blendy JA, Oslin D, Goldman D, Anton RF. The role of the Asn40Asp polymorphism of the mu opioid receptor gene (OPRM1) on alcoholism etiology and treatment: a critical review. Alcohol Clin Exp Res. 2012;36(3):385-94.

48. Miranda R, Reynolds E, Ray L, Justus A, Knopik VS, McGeary J, et al. Preliminary evidence for a gene-environment interaction in predicting alcohol use disorders in adolescents. Alcohol Clin Exp Res. 2013;37(2):325-31.

49. Chassin L, Lee MR, Cho YI, Wang FL, Agrawal A, Sher KJ, et al. Testing multiple levels of influence in the intergenerational transmission of alcohol disorders from a developmental perspective: the example of alcohol use promoting peers and $\mu$-opioid receptor M1 variation. Dev Psychopathol. 2012;24(03):953-67.

50. Van der Zwaluw CS, Otten R, Kleinjan M, Engels RCME. Different trajectories of adolescent alcohol use: testing gene-environment interactions. Alcohol Clin Exp Res. 2014;38(3):704-12.

51. Pieters S, Zwaluw CSVD, Vorst HVD, Wiers RW, Smeets H, Lambrichs E, et al. The moderating effect of alcohol-specific parental rule-setting on the relation between the dopamine $\mathrm{D} 2$ receptor gene (DRD2), the mu-opioid receptor gene (OPRM1) and alcohol use in young adolescents. Alcohol Alcohol. 2012;47(6):66370.

52. Perreau-Lenz S, Spanagel R. Clock genes $\times$ stress $\times$ reward interactions in alcohol and substance use disorders. Alcohol. 2015;49(4):351-7.

53. Rosenwasser AM, Fecteau ME, Logan RW. Effects of ethanol intake and ethanol withdrawal on free-running circadian activity rhythms in rats. Physiol Behav. 2005;84(4):537-42.

54. Dong L, Bilbao A, Laucht M, Henriksson R, Yakovleva T, Ridinger $\mathrm{M}$, et al. Effects of the circadian rhythm gene period 1 (Per1) on psychosocial stress-induced alcohol drinking. Am J Psychiatry. 2011;168(10):1090-8.

55. Kovanen L, Saarikoski ST, Haukka J, Pirkola S, Aromaa A, Lönnqvist J, et al. Circadian clock gene polymorphisms in alcohol use disorders and alcohol consumption. Alcohol Alcohol. 2010;45(4):303-11.

56. Blomeyer D, Buchmann AF, Lascorz J, Zimmermann US, Esser G, Desrivieres S, et al. Association of PER2 genotype and stressful life events with alcohol drinking in young adults. Le Foll B, editor. PLoS ONE. 2013;8(3), e59136.

57. Enoch M-A. Genetic influences on the development of alcoholism. Curr Psychiatry Rep. 2013;15(11):1-9.

58. Perry BL, Pescosolido BA, Bucholz K, Edenberg H, Kramer J, Kuperman S, et al. Gender-specific gene-environment interaction in alcohol dependence: the impact of daily life events and GABRA2. Behav Genet. 2013;43(5):402-14.

59. Laas K, Reif A, Kiive E, Domschke K, Lesch K-P, Veidebaum T, et al. A functional NPSR1 gene variant and environment shape personality and impulsive action: A longitudinal study. J Psychopharmacol (Oxf). 2014;28(3):227-36.

60. Rizzi A, Vergura R, Marzola G, Ruzza C, Guerrini R, Salvadori S, et al. Neuropeptide $S$ is a stimulatory anxiolytic agent: a behavioural study in mice. Br J Pharmacol. 2008;154(2):471-9.

61. Laas K, Reif A, Akkermann K, Kiive E, Domschke K, Lesch K-P, et al. Neuropeptide $\mathrm{S}$ receptor gene variant and environment: contribution to alcohol use disorders and alcohol consumption. Addict Biol. 2015;20(3):605-16.

62. Salvatore JE, Aliev F, Edwards AC, Evans DM, Macleod J, Hickman M, et al. Polygenic scores predict alcohol problems in an independent sample and show moderation by the environment. Genes. 2014;5(2):330-46. Methodologically rigorous study that derives a polygenic risk score for alcohol use in one sample and uses it in another sample with rich measures of the environment to (a) replicate the association with alcohol use and (b) show moderation by environmental factors. 
63. Duncan LE, Keller MC. A critical review of the first 10 years of candidate gene-by-environment interaction research in psychiatry. Am J Psychiatry. 2011;168(10):1041-9.

64. Kendler KS, Gardner CO. Interpretation of interactions: guide for the perplexed. Br J Psychiatry. 2010;197(3):170-1.

65. Hussong AM, Curran PJ, Bauer DJ. Integrative data analysis in clinical psychology research. Annu Rev Clin Psychol. 2013;9(1):61-89.
66. Widaman KF, Helm JL, Castro-Schilo L, Pluess M, Stallings MC, Belsky J. Distinguishing ordinal and disordinal interactions. Psychol Methods. 2012;17(4):615-22.

67. Aliev F, Latendresse SJ, Bacanu S-A, Neale MC, Dick DM. Testing for measured gene-environment interaction: problems with the use of cross-product terms and a regression model reparameterization solution. Behav Genet. 2014;44(2):165-81. 